\title{
COGNITIVE STRATEGIES OF POETIC TEXT INTERPRETATION
}

\section{Bieliekhova L. I.}

\section{INTRODUCTION}

It is commonly acknowledged that poetic language is essentially different from the ordinary language, but nevertheless most people understand poetry. Great poets can speak to us because they use the modes of thought we all possess. Using the capacities we all share, poets can illuminate our experience, explore the consequences of our beliefs, challenge the way we think. To understand the nature and value of poetic creativity requires us to understand the ordinary way we think ${ }^{1}$. Cognitive linguists proved that metaphor is not a matter of words but a matter of thought - in all kinds of thought: thought about emotion, about society, about human character, and about nature of life and death ${ }^{2}$. It is indispensable not only to our imagination but also to our reason. Metaphor is a tool so ordinary that we use it unconsciously and automatically in everyday life. Poetic metaphor is highly elaborated, and still we trigger its meaning. It is explained by the fact that in composing and reading poetry, poets and readers use the same cognitive principles of embodied understanding. We both create and conceptualize our world through similar schemas or schemata. In order to obtain an adequate or prototypical reading of a poetic text (M. Freeman's term) one should use an adequate cognitive model of its interpretation.

The article focuses on cognitive approach to the poetic texts interpretation and intends to demonstrate cognitive mechanisms underlying the formation of poetic images. Its major concern is working out an integrated cognitive model of poetic texts interpretation. It is claimed that such a model envisages two main strategies of poetic text processing: imagery space exploration and text world navigation.

It is assumed that verbal poetic images constitute the dominant of a poetic text message and that text formation as well as the function of

1 Lakoff George, Turner Mark. More than Cool Reason: A Field Guide to Poetic Metaphor. Chicago: The University of Chicago Press. 1989. P. xi)

${ }^{2}$ Lakoff George, Johnson Mark. Philosophy in the Flesh: The Embodied Mind and its Challenge to Western Thought. N. Y.: Basic Books 1999. P. 9-10 
textual elements are regulated by some cognitive mechanisms. Any text has a "presumption of interpretation". In the text there exists a program of its interpretation, the strategies and tactics of correlation of text semantics with the knowledge about the structure of communication that are embodied in the text ${ }^{3}$. Interpretations of one and the same text may be different. There exist, for instance, seventy-nine conflicting interpretations of a poem by E. Dickinson "My Life had stood - a Loaded Gun"4. The multiplicity of interpretations occurs because of various interpretative strategies and tactics involved in text comprehension and different scientific approaches to the study of text. Within the cognitive theory poetic texts are the products of cognizing minds and their interpretations are the products of other cognizing minds in the context of the physical and socio-cultural worlds in which they have been created and are $\mathrm{read}^{5}$. It is claimed in this paper that 'imagery space exploration' can be treated as cognitive strategy in poetic texts interpretation, as far as it is intended on revealing the linguistic and cognitive mechanisms of verbal poetic images formation and functions in the imagery space of a poetic text.

Cognitive turn in conceiving of the nature of poetic tropes and figures of speech, the further elaboration of the theory of conceptual metaphor and metonymy ${ }^{6}$, conceptual integration and mental spaces ${ }^{7}$ led to reevaluation of the traditional views on the theory of verbal poetic image.

It is hypothesised that a verse represents a poetic imagery space that can be regarded as the medium where everyday concepts undergo modifications and become poetic images. The image landscapes of poetic texts differ from each other in the way poetic images are interwoven in them. Such an approach makes it possible to penetrate into image relations within the text and to define the types of images in textual worlds, which in

${ }^{3}$ Vorobyova Olga"Linguistic Signals of Addressee-Orientation in the Source and Target Literary Text: A Comparative Study". CSL 32 Papers from the Parasession on Theory and Data in Linguistics. Chicago: Chicago Linguistic Society. 165-180.1996. P. 166.

${ }^{4}$ Freeman Margaret. Emily Dickinson and the discourse of intimacy. / Semantics of Silence in Language and Literature G. Grabher, U. Jessner (eds.). Heidelberg: Universitat C. Winter.1996. P. 192.

${ }^{5}$ Freeman Margaret. Minding: Feeling, form, and meaning in the creation of poetic iconicity. In: Cognitive Poetics: Goals, Gains, and Gaps. Berlin: Mouton de Gruyter. 2009. P. 169-196. Freeman, Margaret H. Poetry and the Scope of Metaphor: Toward a Cognitive Theory of Literature. In: Metaphor and Metonymy at the Crossroads. A Cognitive Perspective. Berlin, New York.: Mouton de Gruyter. 2000. P. 253 - 283.

${ }^{6}$ Lakoff G., Johnson M. Metaphors We Live By. Chicago: The University of Chicago Press. 1980.

${ }^{7}$ Fauconnier G. Turner M. The Way We Think: Conceptual Blending and the Mind's Hidden Complexities. N.Y. : Basic Books, 2002. 
its turn will lead to more adequate interpretation of the message of a poetic text, to its deep hermeneutic understanding.

This assumption is drawn while investigating the mechanisms of verbal poetic images' formation and functioning in a verse from a cognitive viewpoint in terms of prototypes semantics. In this light a poetic image is seen as a textual construal and a cognitive structure which has two planes conceptual and verbal. It is a multifaceted phenomenon, a verbalized knowledge in the text construed by pre-conceptual, conceptual and language domains. Pre-conceptual domain rooted in the cognitive unconscious $^{8}$ is an implicative matrix of the "collective unconscious" which underlies each poetic image. It is an archetype revealed in human's mind through consciousness as archetypal image-schemas. An archetype is a gestalt structure, eidos of the image, its aura. It resides in the unconscious conceptual system and functions as "hidden hand" that shapes how the human being conceptualizes all aspects of his experience ${ }^{10}$. Conscious thought is the tip of an enormous iceberg. Unconscious thought is 95 per cent of all thought and it shapes and structures all conscious thought ${ }^{11}$. The latter is structured by archetypal image-schemas. "Archetypal patterns flourish on the fairy-tale land of poetry"12. It means that archetypal imageschemas give rise to verbal poetic images through cognitive operations of extension, elaboration and composition via conceptual metaphors, metonymies and oxymora.

Image-schemas are viewed as cognitive units for storing and processing the information, knowledge of the image picture of the world. Imageschemas are the result of extension of eidetic (holistic, gestalt) archetypal image into logos (discrete) image structured by conceptual domains related to metaphoric or metonymic projection of the world. Image-schema reflects general capacity of a human being to conceptualization of reality by metaphorical mapping of one conceptual domain onto another ${ }^{13}$. Thus, archetypal perception of DEATH as something awful, incomprehensible,

${ }^{8}$ Lakoff G., Johnson M. Philosophy in the Flesh: The Embodied Mind and its Challenge to Western Thought. N. Y. : Basic Books .1999. P. 121.

${ }^{9}$ Юнг К. -Г. Архетипы и символ М.: Renaissance, 1991. с. 98.

${ }^{10}$ Lakoff, Johnson. Philosophy in the Flesh: P. 12.

${ }^{11}$ Lakoff, Johnson. Philosophy in the Flesh: P. 13.

12 Campbell J. The Inner Reaches of Outer Space: Metaphor as Myth and as Religion. N. Y., Toronto: Harper and Row Publishers, 1988. P.17.

${ }^{13}$ Johnson The Body in the Mind: The Bodily Basis of Meaning, Imagination. Chicago : The University of Chicago Press,1987. P. xxi. Freeman Margaret. Poetry and the Scope of Metaphor: Toward a Cognitive Theory of Literature. / Metaphor and Metonymy at the Crossroads. A Cognitive Perspective. Berlin, New York. : Mouton de Gruyter, 2000. P. 256. 
dark is transformed into archetypal image-schema DEATH IS DARKNESS. Further extension of this schema via cognitive operations of specification and elaboration may lead to different configurations of image-schemas within verbal poetic image. For instance, R. Frost's poetic image "I have been one acquainted with night" (Frost P: 146) contains several conceptual schemas: DEATH IS DARKNESS; NIGHT IS DARKNESS (metaphors); NIGHT stands for DEATH (metonymy); DEATH IS A LIVING THING (metaphor which personifies death and draws the conclusion that one can be acquainted with it).

\section{Imagery space exploration}

Imagery space exploration is recognized as the main cognitive tracks, which show how poetic images interact within the space illuminating the paths of interpretative strategies of the text.

Image space of poetic texts of contemporary American poetry is regarded as a part of semiotic sphere of American culture, which is both the result and the product of culture development.

A poetic image is a verbal embodiment of the configuration of various conceptual schemas. The core of conceptual plane of a verbal poetic image is prototypical schema. Any poetic image descends to archetype which is further transformed into an archetypal image-schema. As distinct from the latter prototypical image-schema is a generalized, stereotyped schema which underlies a group of similar poetic images constituting a prototypical category. For example, the verbal poetic image " $a$ two-horn silver moon" (Sandburg CP: 286) enters a row of similar images: "he candles of the moon" (Sandburg CP: 261), "when the moon was a hammock of gold" (Sandburg CP: 406), "cradle moon rides" (Sandburg CP: 89). In all of the images the moon is compared to a THING on the ground of FORM. The lexical embodiment of the elements of the image may change, but all the images are united into one category by virtue of the same prototypical schema MOON IS A THING which underlies each image.

The prototypical schema is embodied via respective conceptual metaphor and metonymy in various verbal poetic images:

I. "I know that life is like an ocean" (Ashbery NA: 1270), "the gulf of the rest of my life" (Hull MV: 34), "in a shower of all my days" (Thomas MV: 201), "this river of young woman life" (Sandburg CP: 334) - LIFE IS WATER (metaphor).

II. "life is a prolonged waltz of changes" (Koestenbaum 35: 201), "life can climb back up a stream of radiance to the sky" (Frost P: 112), "...across slow, short years..." (Sandburg CP: 134), "and half his lifetime 
lapsed in the hot race” (Owen 35: 314), “...cat crouch of ages” (Sandburg CP: 456) - LIFE IS MOTION (metaphor).

III. "My Life had stood - a Loaded Gun" (Dikinson NA: 231), "the butt ends of my days" (Rich NA: 1159), "a future stuck in its circuit like a gun" (Koestenbaum 35: 114) - LIFE IS ARTIFACT (metaphor)

IV. "I have measured out my life with coffee spoons" (Eliot MV: 101), "In the prison of his days" (Skelley BBAP: 371) - LIFE IS A CONTAINER (metaphor).

V. "But I have promises to keep

And miles to go before I sleep.

And miles to go before I sleep" (Frost P: 194),

"Two roads diverged in a wood, and I - I took the one less travelled by" (Frost P: 223) - ROAD (part) stands for LIFE (whole) (metonymy associated with conceptual metaphors LIFE IS MOTION, LIFE IS A JOURNEY).

Besides conceptual metaphor and metonymy in the frameworks of this research we advice conceptual oxymoron. It is proved that the degree of novelty of verbal poetic images is predetermined by the type of conceptual oxymoron that underlies their verbal form. Conceptual oxymora reflect a paradoxical way of conceiving of attributes and properties of things, objects, or phenomena of life. Exploration of novel verbal images through the lens of G.Lakoff's theory of metaphor and Ch. Fillmore's frame semantics led to the conclusion that cognitive operations of overlaying, overlapping and clashing serve as a criterion for classification conceptual oxymora into ontological and epistemic (further subcategorized into structural and orientational). Ontological conceptual oxymora such as POSSIBLE VS. IMPOSSIBLE, ALLOWED VS. NON-ALLOWED, EVIL VS. VIRTUE, BEAUTIFUL VS. UGGLY underlie archetypal and stereotypal verbal poetic images like "sinful pleasures", "awfully beautiful", "unbearable happiness", "a perfect fool", - formed as a result of overlaying an ontologically correspondent attribute of one entity onto an opposite member of the same domain. The cognitive operation of overlapping the entities that structure the conceptual domains of contradictory objects, things or phenomena underlie idiotypal poetic images which descend to structural conceptual oxymoron: "sweet pain", "clinking silence", "My life has been a joke, a dance that walked, a song that spoke" (Angelow 35: 11), "her eyes glared with cold fire" (Wylie MV: 823). Epistemic orientational oxymoron HERE VS. THERE, HERE/THERE VS. NOWHERE, PRESENT VS. PAST, PAST VS. FUTURE, FUTURE VS. PRESENT, GOOD VS. BAD underlie kainotypes: "Progress is a comfortable disease" (Cummings MV: 235), 
"leading up the stairs going down" (Levertov MV: 368), "The imperfect is our paradise" (Stevence NA: 1210), - formed as a result of clashing the frames of knowledge entrenched in human's conscience and those verbalized in a poetic expression. Such poetic images challenge or change our understanding or views of things, events, or phenomena of life. The cognitive ground for epistemic oxymora lies in physical experience of space an time and cultural or intellectual experience in moral imperatives.

Conceptual structures of verbal poetic images serve as a parameter for their typological classification as far as they manifest the so called "space and time" aspects in the formation of conceptual configurations. Conceptual analysis of rich empirical data obtained from contemporary American poetry suggested figuring out two groups of poetic images: the old (archetypes and stereotypes) and new ones (idiotypes and kainotypes as idios from Greek - special, kainos - new).

A stereotypal verbal poetic image is defined on the criteria of function and frequency of usage. A poetic image acquires a status of stereotype due to the frequency of its use in a cultural community and the well-established identity of its authorship. It is entrenched into the community conscience through generalization as a cognitive procedure and intertextualization as a result of its frequent use by other poets. The stereotypal verbal image in the first group of images given below is "the river of life" as it has a definite aurthor (Homer) and frequent citation by different poets through centuries. Besides it descends to an archetypal image "the river of Lethe".

Idiotype is a prototype's modification preferred by a particular writer. It is a complex image which reflects idiolect and idiostyle of the author, his peculiarities of world perception. Idiotype is built on the basis of a certain prototype and a set of isotypes (similar images). Among idiotypes there can be found kainotypes, or the concepts the novelty of which provide a breakthrough into a new conceptual domain. In certain cases a clash between the image space of the archetype and the image space of the idiotype gives birth to a kainotype.

Within a poetic imagery space we observe the extension: archetype $\rightarrow$ prototypes $\rightarrow$ idiotypes $\rightarrow$ kainotypes. Conceptual metaphor serves as a cognitive mechanism to trigger this extension. Another mechanism which performs the same function is conceptual metonymy. This statement can be illustrated by the prototype HUMAN LIFE (whole) is MOTION (part). Specification of this prototypical schema results in the sub-schemas HUMAN LIFE is AN INTENDED MOTION. The sub-schema is developed into the idiotypes: HUMAN LIFE IS A RACE (and half his lifetime lapsed in the hot race: Owen 35: 314), LIFE is A JOURNEY (two roads diverged in a wood, and I - I took the one lest traveled by: (Frost 
P: 223). Frost's idiotype is modified into the kainotype: but I have promises to keep and miles to go before I sleep: (Frost P: 194), where the image of INTENDED MOVEMENT overlaps with the image of DUTY to be carried out by humans.

Analogical reasoning as a general principle of cognitive analysis serves the unfolding mechanism of image formation in the imagery space of a poetic text. This principle illuminates how the elements of one cognitive domain are mapped onto another, explicating the nature of linguistic phenomena occurring in the creation of images such as metaphor, metonymy, oxymoron and all types of repetitions ${ }^{14}$.

It is claimed in this paper that besides analogical and associative mapping which underlie the formation of certain types of poetic images there also exist contrastive and constructional types of mappings. Mapping is universally recognized as a cognitive operation of drawing analogies using different skills of seeing similarity ${ }^{15}$. A variety of constructions involving analogy, metaphor, and hedges set up multi-space configurations with source, target, generic and blended spaces that project onto each other in several directions ${ }^{16}$. It is assumed that analogical and associative reasoning are central cognitive processes which govern human's conceptualization of reality. Analogical mapping underlies poetic images based on conceptual metaphor, while associative mapping underlies those based on conceptual metonymy. Contrastive or paradoxical are those based on conceptual oxymoron. Similar to the types of conceptual metaphors ${ }^{17}$ the paper suggests classification of conceptual oxymora. It is proved that the degree of novelty of verbal poetic images is predetermined by the type of conceptual oxymoron that underlies their verbal form. The type of a conceptual oxymoron is defined according to the kind of modality: aletic, deontic, epistemic, axiological ${ }^{18}$ - embodied in the verbal structure of a poetic image. Ontological conceptual oxymora POSSIBLE

\footnotetext{
${ }^{14}$ Semino Elena. Language and World Creation in Poems and Other Texts. London, New York : Longman, 1997. P. 138-141.

${ }^{15}$ Freeman Margaret. Poetry and the scope of metaphor: Toward a cognitive theory of literature / Metaphor and Metonymy at the Crossroads. A Cognitive Perspective. Berlin, N.Y, 2000. P. 256. Freeman, Margaret. Minding: Feeling, form, and meaning in the creation of poetic iconicity / Cognitive Poetics: Goals, Gains, and Gaps. Berlin : Mouton de Gruyter, 2009. P. 169-171.

${ }^{16}$ Fauconnier G. Mental Spaces: Aspects of Meaning Construction in Natural Language. Cambridge : Cambridge University Press, 1994. P. xxv.

${ }^{17}$ Lakoff, Johnson. Metaphors We Live By....P. 10-24.

18 Doležel, Lubomir. Heterocosmica: Fiction and Possible Worlds. Bloomington; London : The John Hopkins

University Press, 1998. P. 113-128
} 
VS. IMPOSSIBLE, ALLOWANCE VS. NON-ALLOWANCE related to aletic and deontic modality underlie archetypal and stereotypal verbal poetic images like "sinful pleasures", "awfully beautiful", formed on the basis of cognitive operation of overlaying an entity of the source domain onto the opposite entity of target domain. Structural conceptual oxymora KNOWLEDGE VS. IGNORANCE reflecting epistemic modality and orientational oxymora: HERE VS. THERE, HERE/THERE VS. NOWHERE, PRESENT VS. PAST, PAST VS. FUTURE, FUTURE VS. PRESENT which show spatial and time relations, underlie idiotypes and kainotypes: "Eternity - the Untold story" (Dickinson NA: 232 ), "Progress is a comfortable disease" (Cummings MV: 103), "The imperfect is our paradise" (Stevens MV: 516), "You are my future of the past" (Bly MV: 87), "leading up the stairs going down" (Levertov MV: 367) - formed as a result of clashing or overlapping entities of source and target domains.

It is well acknowledged that analogical mapping covers a set of attributive, situational and relative cognitive operations within different domains of the imagery space ${ }^{19}$. We suggest constructional mapping as an operation of cognitive and linguistic nature. It is traced at all linguistic levels: phonetic, morphological, lexical and syntactic. Constructional mapping is manipulation with linguistic units of verbal expressions, which results in emergence of novel verbal forms, neologisms or additional meanings. For instance: "Where are the snows of yesteryear?" (Sandburg, CP: 572); "There's the grief of yesteryear" (Snyder BBAP: 467). Neologism is formed by blending two words: yesterday and year. In verbal images: "The evily compounded, vital I" (Stevens MV: 516), "All is new and near in the unchanging Here" (Muir BBAP: 341), "they are not the me Myself" (Whitman WW: 346) - the properties of noun are mapped i.e. projected on the properties of pronouns and adverb.

Thus, the strategy of imagery space exploration is realized by the cognitive operations of different mappings: conceptual (analogical, associative and contrastive) as well as linguistic (constructional) and cognitive procedures of generalization, extension, combination, completion, elaboration, intertextualization, overlaying, clashing and overlapping.

${ }^{19}$ Freeman Margaret. Poetry and the scope of metaphor: Toward a cognitive theory of literature / Metaphor and Metonymy at the Crossroads. A Cognitive Perspective. Berlin, N.Y, 2000. P.256. 


\section{Text world navigaton}

Image space exploration is regarded as a starting point in the interpretation of the poetic text world. The next strategy in the text processing is text world navigation, which is realized by the cognitive operations of reconstruction of mental spaces. It is based on the possibleworld theory, complemented by schema-theory and basic assumptions of the theory of cognitive metaphor and conceptual integration (blending). Mental spaces are small conceptual packets constructed as we think and read, for purposes of understanding and interpretation of verbal poetic images. Conceptual blending operates over mental spaces as inputs. In blending, structure from two input spaces is projected to a separate space, the blend. Once the blend is established we can operate cognitively within that space. Blended spaces are sites for central cognitive work ${ }^{20}$.

Poetic text world is viewed as a cognitive construal which arises as a result of interpretation between reader and the language of the text. More precisely, a text world corresponds to the configuration of schemata that are instantiated by a reader during the processing of the text. It is assumed in the paper that possible world models are rather limited in their treatment of figurative language. Their main contribution is to highlight the fact that literal and figurative language have opposite ontological implications. Possible world theory allows the description and classification of the poetic text worlds on the bases of accessibility relations that link them to the actual world, but it is generally insensitive to the linguistic make up of the texts in the projection of the text worlds ${ }^{21}$. Schema theory approach is systematically related to a linguistic analysis of the poetic texts. Linguistic data serve as triggers for selecting the necessary schemata.

Texts may challenge or confirm existing readers' beliefs and assumptions. A schema-theory approach helps to pin down the way in which the readers' background knowledge interacts with the language of the texts and show how the former is altered or reinforced.

Schema is a cluster of knowledge representing a particular generic procedure, object, percept, event, sequence of events, or social situation ${ }^{22}$. It is a cognitive model of some aspect of the world that is used in

${ }^{20}$ Fauconnier G. Mental Spaces: Aspects of Meaning Construction in Natural Language. Cambridge : Cambridge University Press, 1994. Turner, Mark and Fauconnier Gilles. "Metaphor, Metonymy, and Binding". Metaphor and Metonymy at the Crossroads. A Cognitive Perspective. Berlin, N.Y. : Mouton de Gruyter, 2000. P. 133-141.

${ }^{21}$ Semino Elena. "Text worlds". Cognitive poetics: Goals, Gains and Gaps. Berlin. New York : Mouton de Gruyter, 2009. P. 67.

${ }^{22}$ Holyoak, Keith James and Paul Thagard. Mental Leaps: Analogy in Creative Thought. Cambridge, MA: The MIT Press / Bradford Books,1995. P. 19. 
comprehending human's experience and in reasoning about $\mathrm{it}^{23}$. Schema and schemata underlie metaphorical relationships, as well as describe the different ways in which such connections may be established ${ }^{24}$. In our view the use of schemata is motivated by the need to provide an answer how one domain of the image reminds us of another. Reminding is central to comprehension as it involves finding the correct memory structure to process the verbal poetic image. Stereotypes and archetypes correspond to memory structures in this work. The notion of prototypical image-schemas corresponds to the notion of schemata reinforcement. Stereotypal and archetypal verbal poetic images trigger the readers' reinforcement schemata which help to reconstruct the prototypical meaning of the poem. Idiotypical images trigger refreshment schema. The latter challenge and potentially refresh the readers' existing sets of beliefs and assumptions and contribute to the creation of a text world that readers perceive as unconventional or novel. Idiotype's potential for schema refreshment can be explained by the cognitive mechanism of its formation in the text. Idiotypical verbal images are construed by relational and situational mapping, the aim of which is not the perceiving similarity between two domains as it takes place in the formation of stereotypes, but the creation of similarity, which leads to the attribution of new properties to the target (tenor) domain.

Kainotypes construed on complex mapping besides refreshment schema trigger revelation schema, which lead to construction of a new reality or a new attitude to a world constructed in the textual world of a poem.

Poetic text world is viewed as a cognitive construal which arises as a result of interpretation between reader and the language of the text. More precisely, a text world corresponds to the configuration of schemata that are instantiated by a reader during the processing of the text. Linguistic data serve as triggers for selecting the necessary schemata.

Texts may challenge or confirm existing readers' beliefs and assumptions. A schema-theory approach helps to pin down the way in which the readers' background knowledge interacts with the language of the texts and show how the former is altered or reinforced.

${ }^{23}$ Lakoff, George. Women, Fire and Dangerous Things: What Categories Reveal About the Mind. Chicago: University of Chicago Press, 1987. P. 65.

${ }^{24}$ Semino, Elena. "Schema theory and the analysis of text worlds". Language and Literature vol. no. 2. P 80. 


\section{Illustrations}

The way the integrated cognitive model of interpretation of poetic textual world works can be illustrated by interpretation of C. Sandburg's verse "Guaranteed Antique":

Life is just a bowl of cherries.

Death is a kiss and an ashtray.

Suppose Judas Iscariot

had written Mary Magdalene:

"I love you, I love you."

Would Mary have answered:

"You? ...You? Since when?"

Life is just a bowl of cherries.

Death is a kiss and an ashtray.

(Sandburg, CP: 660)

Image space exploration of the verse one should start with identification of stereotypal images which are based on prototypical imageschemas: LIFE IS A CONTAINER, DEATH IS A GOOD BUY, DEATH IS A CONTAINER. They are construed on the commonly recognized associations of a funeral ritual of kissing a deceased on the forehead, and an urn as a container of ashes. All these stereotypes descend to archetypes of LIFE and DEATH. The latter give rise to prototypical image schemas LIFE IS A FRUIT OF KNOWLEDGE, LIFE IS A CONTAINER which are variously verbalized by different authors, depending on the archetypal symbols that exist in this or that cultural community. Thus, the prototype image-schema LIFE IS A FRUIT is verbalized in different verbal poetic images: "Life is just a bowl of cherries" (Sandburg: 660), "the apple of life" (Willbur: 589), "her days like a pomegranate" (Lowell: 567). The Biblical archetypal symbol "apple" has been transformed in historical tradition into grapes (Roman culture), cherries (anglo-saxon and scandinavian cultures) ${ }^{25}$. The prototype LIFE IS A CONTAINER entails various verbal poetic images besides mentioned above C. Sandburg's, for instance, "the cup of her life" (Tylor: 456), "Yes, death is at the bottom of the cup / And everyone that lives must drink it up" (Howells: 831), "I have measured out my life with coffee spoons" (Eliot: 254).

${ }^{25}$ A Comprehensive Dictionary of Literature Chief Editor \& Compiler: Julien D. Bonn. Dehli : Abhishek Publications, 2010. P. 27, 156. 
The further track of image space exploration leads to explication of symbolic poetic allusions to the Biblical names of Judas Iscariot and Mary Magdaline. The second stanza of the verse is presented in the form of a supposed dialogue between Judas and Mary. The Subjunctive Mood of the predicates gives no offer of the reference time of the event described. The author's intention presupposes an ideal reader who is familiar with the Bible and its various interpretations. He gives the reader a choice of possible interpretations.

The repetition of the first stanza at the end of the verse serves as a device to create a circle and thus to actualize an archetype of HARMONY. This archetype dominates the whole text and the clue to it is in the title of the verse. The title "Guaranteed Antique" can be seen as an avenue of the text interpretation, the coded program of image space interpretation. It can be read as "ensured by the traditions in world culture".

A further interpretation of the verse recruits a text world navigation model, which exploits possible world theory ${ }^{26}$ and schemata theory framework $^{27}$.

The second stanza presents itself as a contra-text, an embedded text or text-intruder, which suggests that a hypothetical world is quite compatible with an actual one. It may be treated as a parallel world aimed at shifting the focus of a reader from the first and the third stanzas where the world is depicted as a conventionally arranged construal. The function of stereotypal images used in the first and the third stanzas lies not in creating a new world but rather in sustaining this conventional view on it, in reinforcing readers' schemata. There is no clash between the worlds described in the verse. The purpose of a hypothetical world presented by text intervention of the second stanza is to challenge readers' knowledge of basic archetypes of life and to confirm the universally acknowledged truth that nothing can be changed in history as it is "guaranteed by antique".

The repetition of the first stanza at the end of the verse serves as a device to create a circle and thus to actualize an archetype of HARMONY. This archetype dominates the whole text and the clue to it is in the title of the verse. The title "Guaranteed Antique" can be seen as an avenue of the text interpretation, the coded program of image space interpretation. It can be read as "ensured by the traditions in world culture".

${ }^{26}$ Ryan, Marie-Laure. Possible Worlds, Artificial Intelligence and Narrative Theory. Bloomington: Indiana University Press, 1991.

${ }^{27}$ Semino, Elena. "Text worlds". Cognitive poetics: Goals, Gains and Gaps. Berlin. New York : Mouton de Gruyter, 2009. P. 33-77. 


\section{CONCLUSIONS}

The change of paradigms in the study of a text as a verbal object from language-centered through text-centered to knowledge-centered - has brought to the forefront the assumption that text formation as well as the function of textual elements are regulated by certain cognitive mechanisms.

In the framework of cognitive linguistics a poetic image is viewed as a textual construal and a cognitive structure which has two planes conceptual and verbal. The conceptual plane of the image is understood as a unity of the eidetic (holistic) and the logic (discrete). Conceptual analysis of rich empirical data obtained from contemporary American poetry suggested figuring out two groups of verbal poetic images: the old (archetypes and stereotypes) and new ones (idiotypes and kainotypes).

Analogical and associative reasoning as general principles of cognitive analysis serve the unfolding mechanism of image formation in the imagery space of a poetic text. These principles illuminate how the elements of one cognitive domain are mapped onto another, explicating the nature of linguistic phenomena occurring in the creation of metaphoric and metonymic verbal images. It has been proved that paradoxical thinking lies at the basis of contrastive mapping as mechanism of novel verbal images formation.

Contours of the imagery space in American poetry are revealed via the analysis of conceptual and functional properties that characterize different types of verbal poetic images. The integrative approach to the theory of imagery helped to update the techniques of conceptual analysis of verbal poetic images and to work out the integrative cognitive model of verbal poetic image and imagery space reconstruction.

In any poetic text one can find typologically different verbal images. The way they are interwoven within each other form the ornament of the text, the original landscape of its image space. Stereotypal images constitute its profile. They activate readers' schemata of reinforcement. Their understanding leads to a central, prototypical reading of a text. Archetypal images are the depth of image space, while stereotypes are the width, they reflect cultural traditions of the people. New (novel) images are always highlighted in the text, they make certain meanings of the text more salient, providing its comprehension. Imagery space exploration is a cognitive track for insight text interpretation.

Stereotypal and archetypal verbal images are the anchors of text navigation, they ensure prototypical reading of the text. Novel images (idiotypes and kainotypes) give rise to non-prototypical reading, they 
instantiate the readers' revelation schema and lead to limitless interpretation.

\section{SUMMARY}

The paper focuses on the problem of interpretability of poetic texts and proposes an integrated model of their interpretation. This model is viewed as a cognitive schema (a set of cognitive operations and procedures) of a poetic text processing which may result in prototypical or non-prototypical reading of the text. Prototypical is a central, cognitive reading, the one which explicates an easily recognizable, identifiable message of the text. A non-prototypical reading presupposes multiple interpretations, which might lead either to overinterpretation or to underinterpretation (U. Eco's terms), depending on the cognitive strategies and tactics, employed by the interpreter. Imagery space exploration and text world navigation are regarded as the main cognitive strategies of poetic text interpretation. The first one envisages operations of conceptual analysis of verbal poetic images and their functions in the image space of poetic texts. The second is realized by various cognitive operations and procedures of restructuring text worlds via the analysis of schemata as structures of knowledge verbalized in the poetic text. It is based on the possible world theory, complemented by schema theory and basic assumptions of the theory of cognitive metaphor and conceptual integration (blending).

\section{REFERENCES}

1. Юнг К. -Г. Архетипы и символ. М. : Renaissance, 1991. 306 с.

2. Campbell J. The Inner Reaches of Outer Space: Metaphor as Myth and as Religion. N. Y., Toronto: Harper and Row Publishers, 1988. 286 p.

3. Doležel L. Heterocosmica: Fiction and Possible Worlds. Bloomington; London: The John Hopkins University Press, 1998. 321 p.

4. Fauconnier, Gilles. Mappings in Thought and Language. Cambridge (Mass.): Cambridge Univ. Press., 1994. 190 p.

5. Freeman M. "Emily Dickinson and the discourse of intimacy". / Semantics of Silence in Language and Literature G. Grabher, U. Jessner (eds.). Heidelberg: Universitat C. Winter, 1996.

6. Freeman, Margaret H. Poetry and the Scope of Metaphor: Toward a Cognitive Theory of Literature. I Metaphor and Metonymy at the Crossroads. A Cognitive Perspective. Berlin, New York.: Mouton de Gruyter, 2000. P. 253 - 283.

7. Freeman, Margaret. Minding: Feeling, form, and meaning in the creation of poetic iconicity. /Cognitive Poetics: Goals, Gains, and Gaps. Berlin: Mouton de Gruyter, 2009. P. 169-196. 
8. Holyoak, Keith James and Paul Thagard. Mental Leaps: Analogy in Creative Thought. Cambridge, MA: The MIT Press / Bradford Books, 1995. $286 \mathrm{p}$.

9. Johnson, Mark. The Body in the Mind: The Bodily Basis of Meaning, Imagination. Chicago: The University of Chicago Press, 1987. $227 \mathrm{p}$.

10. Lakoff, George and Mark Johnson. Metaphors We Live By. Chicago: The University of Chicago Press, 1980. 242 p.

11. Lakoff, George and Mark Johnson. Philosophy in the Flesh: The Embodied Mind and its Challenge to Western Thought. N. Y. : Basic Books, 1999. 624 p.

12. Lakoff, George. Women, Fire and Dangerous Things: What Categories Reveal About the Mind. Chicago: University of Chicago Press, 1987. $614 \mathrm{p}$.

13. Lakoff, George and Turner Mark. More than Cool Reason: A Field Guide to Poetic Metaphor. Chicago: The University of Chicago Press, 1989. $190 \mathrm{p}$.

14. Ryan, Marie-Laure. Possible Worlds, Artificial Intelligence and Narrative Theory. Bloomington: Indiana University Press, 1991. 291 p.

15. Semino, Elena "Schema theory and the analysis of text worlds". Language and Literature vol. no. 2, 1995. P. 79-108.

16. Semino, Elena. Language and World Creation in Poems and Other Texts. London, New York. : Longman, 1997. 274 p.

17. Semino, Elena.. "Text worlds". Cognitive poetics: Goals, Gains and Gaps. Berlin, New York : Mouton de Gruyter 2009. P. 33-77.

18. Turner, Mark and Fauconnier Gilles. "Metaphor, Metonymy, and Binding". Metaphor and Metonymy at the Crossroads. A Cognitive Perspective. Berlin, N.Y. : Mouton de Gruyter, 2000. P. 133 - 149.

19. Vorobyova, Olga. "Linguistic Signals of Addressee-Orientation in the Source and Target Literary Text: A Comparative Study". CSL 32 Papers from the Parasession on Theory and Data in Linguistics. Chicago: Chicago Linguistic Society, 1996. P. 165-180.

\section{ILLUSTRATION MATERIALS}

1. AP12 - Twelve American Poets. (1961) Stephen Whicher \& Lars Anebrink.(eds.).

2. New York: Oxford University Press.

3. BBAP - Best of the Best of American Poetry 1998 (2000). Richard Howard (ed.).

4. New York:; Chicago; L.: Holt, Rinehart and Winston Inc. 
5. Cummings SP - Cummings E.E. (1997). Selected Poems 19231958. London; Boston: Faber \& Faber.

6. Frost P - Robert Frost's Poems. (1960). New York; London; Toronto: Washington Square Press, Inc.

7. MV - The Pocket Book: Modern Verse (1958). Oscar Williams. (ed.). New York : Washington Square Press, Inc.

8. NA - The Norton Anthology of American Literature: Third Edition. (1989). New York., London.: W.W. Norton \& Company.

9. Sandburg CP - Sandburg Carl (1970). The Complete Poems. SanDiego; New York; London.: Harcourt Brace Jovanovich Publishers.

10. 35 - Under 35: The New Generation of American Poets (1989). Nicholas Christopher (ed.). New York.; London.; Toronto: An Anchor Book.

11. WW - Western Wind: An Introduction to Poetry (1992). John Frederick Nims (ed.)

12. New York, San Francisco, London., etc. : McGraw - Hill, Inc.

\section{Information about the author:} Bieliekhova L. I.,

Doctor of Philology, Professor, Professor at the Department of the English Language and Methodology of its Teaching, Kherson State University 27, University str., Kherson 73000, Ukraine 